\title{
Incidencia del liderazgo situacional en el índice de satisfacción laboral de los empleados de la ESPAM
}

\section{Incidence of the situational leadership in the labor satisfaction index of the ESPAM employees}

Fabián Eduardo, Álava Rade

Universidad de Especialidades Espíritu Santo, Ecuador

Mayra Liuviana, Vega Chica

Universidad de Especialidades Espíritu Santo, Ecuador

Autor para correspondencia: Éxitos_5@hotmail.com, mvegach@uees.edu.ec Fecha de recepción: 05 de Junio de 2017 - Fecha de aceptación: 30 de Septiembre de 2017

\section{Resumen}

En el presente trabajo se analiza el estilo de liderazgo que existe en la ESPAM y se investiga su incidencia en el índice de satisfacción laboral de los 234 empleados de la institución. Los resultados de esta investigación así como las conclusiones y recomendaciones se exponen en los apartados finales del documento. Dichos resultados demuestran que en la ESPAM existe un estilo de liderazgo de Dirección en equipo, considerado como el ideal ya que promueve un balance entre la orientación a las personas y la orientación a los resultados, adaptándose a las diferentes situaciones e individuos tal como lo requiere el liderazgo situacional, lo cual da como consecuencia un buen ambiente de trabajo y un alto índice de satisfacción laboral.

Palabras Clave: Satisfacción laboral; liderazgo situacional; equipo; estilo

\begin{abstract}
In the following article the leadership style of ESPAM was analyzed to know his incidence in the index of labor satisfaction of 234 employees of the institution. The results of this investigation as well as the conclusions and recommendations are exposed in the final paragraphs of the document. The above mentioned results demonstrate that in the ESPAM there is a leadership style of Direction in equipment considered as the ideal one since he promotes a balance sheet between the orientation to the persons and the orientation to the results, adapting to the different situations and individuals as the situational leadership needs it, which gives as consequence a good environment of work and a high index of labor satisfaction.
\end{abstract}

Key Words: job satisfaction; situational leadership; surveys; team; style 


\section{Introducción}

Toda organización moderna busca ser líder dentro de su área, para lo cual es vital tener clara la visión y misión corporativa, así como los objetivos y los planes de trabajo necesarios para alcanzarlas. Pero éstos no pueden realizarse solos sino que en su ejecución intervienen personas que con sus distintos perfiles profesionales y habilidades logran que los objetivos institucionales se cumplan (Mele, 2012).

Las organizaciones en la actualidad reconocen y valoran el aporte de cada uno de los empleados, ya que entienden que el éxito o fracaso de la empresa no será de ésta como un ente individual, sino un éxito o fracaso colectivo, del conjunto de personas que la conforman. (López, 2011)

En concordancia con el autor Idalberto Chiavenato (2009), el adecuado manejo del talento humano cobra una notable importancia en la actualidad, a fin de beneficiar mutuamente tanto a la organización como a los empleados, procurando siempre un adecuado desempeño laboral y por ende organizacional. Se trata de obtener el denominado "ganar-ganar" entre empresa y empleados, trabajando de manera conjunta y colaborativa para alcanzar las metas planteadas: he ahí la importancia de una eficiente y eficaz administración de los recursos humanos.

La administración de los recursos humanos implica las fases de planeación, organización el desarrollo, la coordinación y el control de técnicas capaces de promover el desempeño eficiente del personal, en medida que la organización representa el medio que permite a las personas que trabajen en equipo, que realicen prácticas donde el personal colabora y se compromete con su labor, con el propósito de alcanzar los objetivos individuales relacionados directamente o indirectamente con el trabajo (Chiavenato, 2009, p. 49).

Los empleados de una empresa de manera contable representan un gasto, sin embargo de manera estratégica, hoy son considerados un activo valioso y las organizaciones están obligadas a realizar esfuerzos para que se sientan bien tratados y estén conscientes de que ellos son lo más importante que la empresa posee, como verdaderos artífices del logro de las metas corporativas. (Gerencie.com, 2008)

En el devenir diario de las empresas, es evidente la importancia mutua que se establece entre el recurso humano y la organización, siendo esta última un medio para conseguir las metas individuales. (Https: //positiviza.wordpress.com, 2013)

Ya no existe el viejo concepto de privilegiar únicamente los intereses de la empresa y sus dueños dejando de lado los intereses de los empleados, sino que hoy se apunta a la mutua satisfacción de necesidades entre todos los integrantes de la organización, para lo cual se promueve una constante medición, seguimiento y mejora del clima laboral así como se realiza un diagnóstico de la relación existente entre directivos y subordinados con el fin de mejorar las relaciones y facilitar la comunicación y el flujo del trabajo. (Ramírez, 2008) 
Se ha comprendido que un adecuado ambiente de trabajo y sanas relaciones profesionales permiten que una organización avance más rápidamente hacia sus metas. El mundo laboral está conformado por relaciones interpersonales entre diferentes individuos, con responsabilidades y necesidades específicas, personales o grupales; es en este medio donde las empresas buscan desarrollar una verdadera sinergia, con el fin de que todos los esfuerzos fluyan positivamente hacia la consecución de las metas de la institución y por ende la satisfacción de las necesidades económicas, profesionales y sociales de los empleados, como una consecuencia del éxito de la empresa. (Bethere, 2012)

Aquellos lugares de trabajo que se caracterizan por su buen clima laboral, obedecen a que su personal siente gran orgullo de pertenecer a la empresa, a lo cual se suma una autoexigencia, entrega y disciplina laboral en cuanto al desempeño de sus funciones y responsabilidades; todo esto va acompañado de un inmenso deseo de asumir nuevas tareas, experiencias y responsabilidades.

Actualmente los empleadores conceden gran importancia a las personas y saben reconocer un trabajo bien hecho y los líderes están prestos a escuchar opiniones de carácter positivo y negativo por parte de los trabajadores, generando una adecuada respuesta al manejar la situación lo mejor posible, efectuando aclaraciones según el caso. También, se potencia la camaradería y se insta a trabajar en equipo, todo esto confluye en que los y las trabajadores/as se sienten más felices y más comprometidos con su organización, aumentando la productividad de la empresa. (Figueroa, 2009).

Se nota la estrecha relación que existe entre un buen clima laboral y la productividad de la organización, dos conceptos que antes se manejaban por separado pero que hoy en día son interdependientes el uno del otro. Actualmente se ha entendido que un buen clima laboral no se logra sólo con el típico plan de incentivos o una promoción de cargo, sino que va más allá: "Un excelente lugar de trabajo no es un conjunto de beneficios, programas o prácticas que se deben dar a los empleados, sino la construcción de relaciones de calidad caracterizadas por la confianza, el orgullo y el compañerismo" (Great Place to Work Institute, 2016).

Como se mencionó con anterioridad, las buenas relaciones, confianza y solidaridad entre las personas que trabajan en una organización son trascendentales, así como también lo es el tipo de líder que esté a la cabeza, cada uno con su estilo de gestión, del cual muchas veces dependerá la motivación, frustración, pesimismo u optimismo del grupo de trabajo. En muchas ocasiones existe un excelente equipo humano, competente y calificado, pero no hay un líder que sepa aprovecharlo adecuadamente, lo cual repercute en los resultados de la empresa. De la misma manera, existen a veces excelentes líderes que están a cargo de equipos de trabajo incompetentes y poco calificados, y su reto será trabajar para sacar lo mejor de cada miembro del equipo y gestionar la mejora del desempeño laboral para el consiguiente logro de resultados a nivel corporativo. (ONGsostenible.org, 2012)

El principal reto para un líder organizacional consiste en contribuir a al logro de los objetivos empresariales, encaminado adecuadamente los esfuerzos, de manera conjunta con los trabajadores. Una de las principales funciones del líder consiste en obtener el mayor potencial de todas y cada una de las personas que pertenecen a la empresa, y a la vez difundir o socializar la 
misión, visión y objetivos que caracterizan a la empresa, procurando sacar el mejor partido a las capacidades, actitudes y aptitudes de cada empleado, a fin de lograr los resultados planteados. La idea es que el líder sepa claramente cuáles son las habilidades personales, sociales y técnicas de cada uno y, en esa medida, potenciarlas en el lugar, tarea o cargo más idóneo, para alcanzar los resultados (Guerrero, 2013).

Como se puede apreciar, el papel vital del líder es indiscutible, razón por la cual éste debe estar debidamente capacitado para actuar de acuerdo a las situaciones que se presenten y a los diferentes perfiles de la gente bajo su responsabilidad, sin olvidarse de que los empleados no están motivados solamente por el salario sino que también les interesa desarrollar su potencial intelectual. El líder debe poseer el suficiente criterio para tener un diagnóstico individual y grupal de su equipo y estar atento no solo a su rendimiento sino a sus necesidades: en gran manera el rendimiento del equipo de trabajo depende de su rol como cabeza. (Blog de Directivos, 2014)

He ahí la justificación de la presente investigación, la cual busca conocer el grado de incidencia que tiene el liderazgo situacional en el índice de satisfacción de los empleados.

La hipótesis de este trabajo es: "El liderazgo situacional tiene incidencia en el índice de satisfacción laboral de los empleados de la ESPAM".

El objetivo general del presente estudio se enfoca en analizar la importancia que tiene el liderazgo situacional en el índice de satisfacción laboral de la Escuela Superior Politécnica Agropecuaria de Manabí (ESPAM) y consecuentemente en el ámbito empresarial en general.

Los objetivos específicos son:

$\checkmark$ Definir los conceptos de liderazgo situacional e índice de satisfacción laboral.

$\checkmark$ Conocer la relación existente entre estas dos variables.

$\checkmark$ Investigar acerca del liderazgo situacional existente en la ESPAM.

$\checkmark$ Investigar acerca de la satisfacción laboral existente en la ESPAM.

Enfrentar los resultados de las investigaciones y concluir si existe o no una relación entre ellos y si la hipótesis se cumple.

Establecer las recomendaciones del presente estudio.

Las variables son:

$\checkmark \quad$ Variable Independiente: Es el liderazgo situacional

$\checkmark$ Variable dependiente: Es el índice de satisfacción laboral

Para desarrollar el presente estudio, se efectuó una revisión de literatura referente al liderazgo situacional y a la satisfacción laboral, así como a la visión actual sobre los recursos humanos, la administración y el desempeño laboral. También se realizó una búsqueda de otras investigaciones similares y aplicación de estudios en instituciones educativas. 
Se aplicaron dos cuestionarios a los empleados de la ESPAM, uno de liderazgo, y el otro de satisfacción laboral, cuyos resultados fueron analizados y confrontados. Se presentan conclusiones y recomendaciones establecidas con el desarrollo del estudio.

\section{Revisión de la literatura}

\section{El Liderazgo}

El liderazgo se puede definir como una relación que se establece entre el denominado "líder" y quienes están bajo su guía, es decir los seguidores, donde ambas partes comparten propósitos comunes, que buscan lograr, asumiendo cada uno la responsabilidad de las funciones, puesto que un buen líder siempre basa sus acciones en obtener resultados mutuamente satisfactorios. (Daft, 2007, p. 27)

Por su parte, Idalberto Chiavenato (2009), señala que el liderazgo es "La influencia interpersonal ejercida en una situación, dirigida a través del proceso de comunicación humana a la consecución de uno o diversos objetivos específicos" (p. 134).

Igualmente, en esta definición se resalta la consecución de objetivos como fin del liderazgo y se señala un elemento importante que es la influencia que ejerce el líder.

Otra definición muy similar a las anteriores pero mucho más conocida es la que hace John Kotter (1996), cuando menciona que el liderazgo se trata de generar cierta influencia que trabaja voluntariamente para alcanzar los objetivos planteados que comparte el grupo laboral (pág. 127).

El Liderazgo es entonces la influencia que se ejerce sobre un grupo humano para avanzar hacia una meta común. Ante lo cual surgen varias dudas:

- ¿Quién o quiénes ejercen este liderazgo en las organizaciones?

- ¿De qué depende el liderazgo?

- ¿Quién es el líder?

El libro "Líder de 360 grados" (2005), escrito por John Maxwell, fue catalogado por el New York Times como la autoridad absoluta sobre Liderazgo a nivel mundial. En dicho libro Maxwell señala que, mayoritariamente, casi todos los casos de liderazgo surgen desde niveles intermedios y generalmente se presenta un solo líder en cada empresa u organización; además, señala que todos, independientemente del nivel en el que cada persona se encuentra, ejerce liderazgo e influencia sobre un grupo personas, un departamento, una empresa, los compañeros, jefes y subordinados, de lo cual se concluye que existe el liderazgo de 360 grados (Acosta, 2014).

El líder de 360 grados se caracteriza por ser una persona diferente, cuyo liderazgo resalta por su actitud, el cual carece de subordinados, porque él cuenta con seguidores. "El líder no impone, inspira" (2005). 
Un líder de 360 grados goza de poseer la facultad o don de influir en las personas de las distintas áreas de una empresa, está presto a brindar su apoyo y ayuda a quienes lo requieran; por tanto, llegar a ser un líder de 360c grados es posible para quienes posean buenas o intermedias habilidades de liderazgo (cinco o seis en una escala del uno al diez), están en capacidad de mejorar y desarrollar la influencia y relaciones personales en una organización, sin importar el nivel organizacional en el que se encuentre (Maxwell, 2005).

\section{Liderazgo Situacional}

De acuerdo a información de la revista Latinoamérica de Psicología (2010), el modelo o teoría de liderazgo situacional (TLS) se popularizó en 1967, año desde el cual se han desarrollados diversas modificaciones, incorporando nuevos parámetros orientados a mejorar la primera versión del libro, Management of Organizational Behavior, de los autores Hersey y Blanchard (1969), incorporando aportes de conocimiento científico alcanzado hasta entonces, respecto del liderazgo.

Los precursores de la TLS fueron dos profesores que perseguían desarrollar un modelo de liderazgo distinto, fundamentado tanto en las situaciones diarias de una organización como en como en la cotidianeidad, modelo que se llamó Liderazgo de Contingencia y luego se fue conociendo como Liderazgo Situacional. (Sharingideas, 2014).

Para Rafael Muñiz (2016), la cualidad del liderazgo eficaz radica en el nivel de adaptación y respuesta que tengan los empleados ante diversas situaciones y cambios del entorno; es decir, se aplica un liderazgo acorde a las necesidades que presenta el equipo laboral. En tal virtud, el liderazgo situacional busca mantener el equilibrio entre dos tipos de comportamiento que ejerce el líder, a fin de adaptarse al nivel de desarrollo que caracterice a su equipo de trabajo (Muñiz R., Marketing21, 2016).

El liderazgo situacional, favorece a que los miembros del equipo se adapten a las diferentes situaciones que se puedan presentar en el giro de negocio.

La Teoría del Liderazgo Situacional (TLS) establece que no existe una fórmula mágica como respuesta ante cualquier situación, al contrario, cada modelo puede adecuarse en función de las características de la situación, ya que, el nivel de conducta del líder obedece a la 'madurez' de los subordinados, lo que implica a la competencia, experiencia, motivación e interés que tienen los subordinados al desempeñar las distintas funciones y tareas encomendadas, asumiendo la responsabilidad del caso. Es así que si los subordinados tienen un grado de madurez bajo, correspondería un estilo de dirección que dé dar órdenes; si el grado de madurez es moderado, el estilo de dirección será persuadir, pero si el grado de madurez de los empleados es alto, el estilo de liderazgo debe ser participar o delegar (Espinosa, 2011).

La explicación que precede permite notar que existe una estrecha relación entre la madurez (perfil) de los miembros del equipo de trabajo y el estilo de liderazgo. Justamente por eso es muy importante que estos dos factores estén en perfecta sintonía y exista la versatilidad del líder para acoplarse a las condiciones del equipo. El líder debe conocer mejor que nadie a su gente: su potencial y sus limitaciones, y estar involucrado en el desarrollo personal y profesional 
de sus miembros; un buen líder tiene buenas relaciones con sus subordinados y se caracteriza por obtener un ambiente laboral sano, productivo y positivo. (Clement, 2011)

\section{Tipos de comportamiento de un líder:}

\section{Comportamiento directivo:}

El líder define las responsabilidades y acciones de los subordinados, ya que éstos no tienen la competencia necesaria para tomar este tipo de decisiones. En este caso el líder decide qué hacer y controla los resultados.

\section{Comportamiento de apoyo:}

En este caso el líder un facilitador que empodera a los empleados para que tomen decisiones y se centra en el desarrollo del grupo.

El líder puede utilizar los dos tipos de comportamiento en mayor o menor medida dando como resultado cuatro estilos de liderazgo: control, supervisión, asesoramiento, delegación.

Estilo control. Alto nivel de comportamiento directivo y un bajo nivel de comportamiento de apoyo.

Estilo supervisión. Altos niveles de comportamiento directivo y de apoyo. Se reconocen los avances y mejoras en el rendimiento.

Estilo asesoramiento. Nivel alto de comportamiento de apoyo y bajo en comportamiento directivo. Las decisiones las toma conjuntamente con los empleados.

Estilo delegación. Bajos niveles en ambos comportamientos debido a que delega la toma de decisiones en sus empleados y los empodera.

Cada uno de los estilos de liderazgo se adapta a los distintos niveles de desarrollo del equipo de trabajo: nivel de desarrollo 1: el líder controla, nivel de desarrollo 2: el líder supervisa, nivel de desarrollo 3: el líder asesora y nivel de desarrollo 4: el líder delega. (Metamanagers, 2016)

\section{El Clima Organizacional y la satisfacción laboral}

El clima organizacional surge debido a la necesidad del ser humano por relacionarse y ajustarse a los cambios complejos del entorno, considerando que las organizaciones están integradas tanto por personas, como por grupos y colectividades que tienen comportamiento distinto, el cual incide en el ambiente laboral (García, 2013, p. 45).

El concepto de clima organizacional fue introducido por primera vez al área de psicología organizacional por Gellerman en 1960. Este concepto estaba influido por dos grandes escuelas de pensamiento: la escuela de Gestalt y la escuela funcionalista. 
Según la escuela de Gestalt los individuos comprenden el mundo que les rodea basados en criterios percibidos e inferidos, de tal manera que se comportan en función de la forma en que perciben su mundo. Es así que el comportamiento de un empleado está influenciado por la percepción que él mismo tiene sobre el medio de trabajo y del entorno (Sarrió, 2014)

Por otro lado, la escuela funcionalista formula que el pensamiento y comportamiento de un individuo dependen del ambiente que le rodea y que las diferencias individuales juegan un papel importante en la adaptación del individuo a su medio (Echegoyen, sf).

El clima organizacional comprende el ambiente interno de toda empresa, e involucra diversos aspectos del entorno que tienen cierto nivel de incidencia, como del entorno como la tecnología, las políticas de la entidad, las metas planteadas, los procesos y reglamentos internos, entre otros, a lo cual se añaden las actitudes, valores y comportamientos de carácter social (Chiavenato, Administración de los Recursos Humanos, 2009).

El clima laboral hace referencia al ambiente en el que los trabajadores desempañan las distintas funciones asignadas a su cargo, de manera cotidiana, a lo que se suma el trato que ejerce el jefe con sus subordinados, la relación establecida entre el personal de la entidad e inclusive, la relación con clientes y proveedores, es decir, el trato existente entre los steakeholders de la empresa (Peralta, 2002).

Considerando lo mencionado en el párrafo anterior, el clima laboral está enfocado como la percepción de los empleados de todo su entorno laboral.

Según Lewin (1936), el clima organizacional proviene del comportamiento humano, el mismo que depende de la situación global donde ocurre la conducta, entendiéndose como "situación global" a la persona y su ambiente psicológico, es decir, el ambiente que es percibido e interpretado por el individuo, conocido también como la conducta ante la interacción personal y situacional (Quintana, 2013).

Ante lo cual, se establece la siguiente fórmula:

$\mathrm{C}=\mathrm{f}(\mathrm{P}, \mathrm{A})$

Donde $\mathrm{C}=$ Conducta

$\mathrm{F}=$ Función

$\mathrm{P}=$ Persona

$\mathrm{E}=$ Ambiente

Para Méndez (2006), el clima organizacional cumple una función destacada en la gestión del personal, llegando a tener un papel protagonista en los últimos, donde las empresas se orientan hacer uso de las distintas técnicas y métodos de análisis e interpretación la gestión del talento humano de la empresa (García, 2013, p. 45).

Por otro lado está Dessler (1976) quien considera que la relevancia del clima organizacional radica en el vínculo que se establece entre los aspectos objetivos de una entidad y el comportamiento subjetivo del personal ante lo cual, hace referencia al enfoque de Forehand y 
Gilmer (1964), quienes establecen el clima como las características de carácter permanente existentes y distintiva de una organización (García, 2013, p. 45).

Aparte de los empleados como tal, en el clima laboral influyen de manera importante factores como la actitud de los administradores, los sistemas de trabajo y los métodos que usan para dirigir y controlar las actividades del equipo humano.

Otros elementos que también inciden en el clima laboral son las relaciones dentro y entre los grupos que comprende cada organización. Es muy importante notar que cuando hay rivalidad, envidia, irrespeto entre los empleados o entre las distintas jerarquías, esto influirá negativamente en el desarrollo de las actividades laborales, a diferencia de las situaciones en que existe camaradería y buena actitud. (Billik, sf)

Existen también factores de naturaleza física que contribuyen al clima organizacional dada su incidencia directa o indirecta sobre la conducta humana. En ellos se encuentran la infraestructura, las facilidades tecnológicas y las condiciones de seguridad del empleado. El espacio físico y condiciones ambientales en donde el empleado lleva a cabo sus actividades diarias, constituyen un elemento fundamental para el óptimo rendimiento y desarrollo de las funciones. (Revista Mercados y Tendencias, 2013)

Un empleado incómodo, adolorido, trabajando en un sitio húmedo, frío, oscuro o demasiado caluroso, difícilmente se hallará a gusto y podrá rendir igual que un empleado que cuente con condiciones de temperatura adecuada, iluminación y confort. Un empleado incómodo se encuentra mucho más irritable y desconcentrado que otro que está en la comodidad de un puesto de trabajo que disfruta y está personalizado según las funciones que éste realiza en la empresa: el primero se sentirá casi humillado al tener que ir a trabajar mientras que el segundo verá posiblemente a su trabajo como su segundo hogar. Las buenas condiciones de trabajo de una persona no solo contribuyen positivamente a su desempeño, sino a su salud física y emocional. (Cevallos, 2013)

Por otra parte, adicional al bienestar que los empleados sienten al contar con un lugar de trabajo acogedor y funcional, hay otro beneficio adicional que tiene este factor para el clima laboral de una empresa y es el sentido de pertenencia. No hay mejor empleado que aquél que se siente "parte de". Este empleado no sólo que trabaja con gusto, llega puntual y está comprometido con la empresa, sino que se siente como parte de una gran familia y su lealtad no tiene límites. Pero aparte del lugar físico y el entorno laboral hay otros aspectos que también pueden darle un sentido de pertenencia al empleado y son factores como: uniformes, espacios de relax comunitarios, eventos corporativos que involucren a sus familias, credenciales, contar con un chat corporativo, entre otros. Es muy importante que cada empresa investigue y analice qué es lo que hace feliz a su gente, qué les motiva, qué les hace ser más productivos, de esta manera podrá estar siempre un paso delante de la competencia, sin olvidarse que la empresa es un organismo vivo, cambiante y susceptible de mejora en todos los aspectos, por lo cual es muy importante el monitoreo constante de todos sus frentes. (Villarreal, 2013)

El Clima Organizacional lo conforman todos los componentes del proceso empresarial: personas, recursos, relaciones, que mediante estrategias motivacionales adecuadas producen 
resultados directos en la calidad de vida de la organización, más específicamente, en su productividad, en la satisfacción de las personas y en el mejoramiento de la imagen y clima organizacional.

El clima laboral se mide a través de indicadores y éstos permiten tomar acciones preventivas y correctivas sobre el mismo, con el fin de que el clima organizacional sea adecuado y se constituya en un factor positivo para que la organización y sus empleados logren los objetivos propuestos. Los indicadores del clima laboral son algunos aspectos que permiten a la empresa conocer información acerca de la denominada "felicidad laboral" de sus empleados, y que se expresa en factores como: ausentismo laboral bajo, baja impuntualidad, buena comunicación entre áreas y entre niveles de mando, respeto, consideración y apoyo entre los empleados, bajo nivel de conflictos, reconocimiento al trabajo de los demás. (Varela, 2015)

Por otra parte, según el enfoque de Litwin y Stringer (1968), se establece que el clima organizacional obedece a elementos formales e informales, que se complementan con factores del entorno como son las actitudes, los valores, la motivación y las creencias que tiene cada persona de la organización.

\section{Medición de la satisfacción laboral}

"En la actualidad las estrategias sobre dirección y desarrollo del personal son el factor más importante que permite el logro de los objetivos empresariales. Dentro de este campo existen procesos que intervienen, tales como: capacitación, remuneración, condiciones de trabajo, motivación, clima organizacional, etc. El factor humano constituye un elemento vital para el desarrollo de los procesos de cualquier organización. Estudios sobre el comportamiento humano han demostrado que cuando un empleado se siente satisfecho y motivado alcanza un desempeño superior en la realización de su trabajo”. (Programa Misión COPEME, 2009).

En la medición del clima laboral es importante saber diferenciar la satisfacción y la motivación, dos conceptos frecuentemente utilizados como sinónimos, pero que implican temáticas distintas y estrategias de gestión diferentes. El hecho de estar satisfecho no asegura que la persona se encuentre motivada, pero ciertamente si te encuentras motivado es un signo de que estás satisfecho. La satisfacción puede disminuir el ausentismo en el trabajo, debido a que los empleados se sienten satisfechos con la labor que desempeñan, en el caso de la motivación hace que los empleados lleguen más allá de solo disminuir el ausentismo, sino que le ponen empeño a las labores que realizan, pudiendo dar más de lo solicitado. (Restrepo, 2013)

La herramienta a utilizarse para conocer la satisfacción de los empleados es la encuesta de Clima Laboral mientras que en el caso de la motivación se requiere de un trabajo personalizado y más profundo, que se puede realizar a través de un focus group o una entrevista personal con cada uno de los empleados conociendo que aspectos son los que lo motivan y cuáles le desmotivan.

Para una evaluación integral de la satisfacción laboral es vital no quedarse con los resultados de la encuesta de clima laboral sino encontrar aquellos aspectos que realmente valoran los empleados ya que puede darse el caso que exista aspectos en los que no estén satisfechos 
pero que no son relevantes para ellos, por lo que será necesario profundizar dichos aspectos. Sobre los aspectos priorizados se tendrá que realizar los planes de acción. (Flores, 2012)

\section{Preguntas clave para la elaboración de la Encuesta de Satisfacción laboral}

En una encuesta para medir la satisfacción laboral deben estar presentes algunas preguntas básicas sobre los aspectos clave del clima organizacional.

Jorge Ignacio Mata Arribas, señala lo siguiente, y sugiere estos temas a consultar:

$\checkmark$ "No conozco, a día de hoy, un método más simple y efectivo para medir la fortaleza de los puestos de trabajo de una empresa que estas 12 cuestiones.

$\checkmark$ Sé lo que se espera de mí en el trabajo.

$\checkmark$ Tengo el equipo y los materiales que necesito para hacer bien mi trabajo.

$\checkmark$ En mi trabajo, tengo cada día la oportunidad de hacer lo que mejor sé hacer.

$\checkmark$ En los últimos siete días, he recibido reconocimiento o elogios por un trabajo bien hecho.

$\checkmark$ Mi jefe/supervisor o alguien más en el trabajo, muestra tener interés en mí como persona.

$\checkmark$ Hay alguien en mi trabajo que estimula mi desarrollo personal y profesional.

$\checkmark$ En el trabajo, mis opiniones cuentan.

$\checkmark$ La misión o propósito de la empresa, me hace sentir que mi trabajo es importante.

$\checkmark$ Mis compañeros de trabajo están dedicados y comprometidos a hacer un trabajo de calidad.

$\checkmark$ Tengo un(a) mejor amigo(a) en el trabajo.

Durante los últimos seis meses, alguien en el trabajo me ha hablado sobre mi progreso.

Este último año, he tenido oportunidades de aprender y crecer personal y profesionalmente en el trabajo.

Si se da cuenta, estas doce preguntas cubren prácticamente todas las necesidades que un trabajador puede tener en cualquier compañía, empezando desde las más básicas (como saber lo que se debe hacer o tener los recursos necesarios) hasta las más elevadas (de desarrollo personal e integración en el grupo)." (Arribas, 2013)

\section{La ESPAM}

La Escuela Superior Politécnica Agropecuaria de Manabí también conocida como ESPAM es un centro educativo de nivel superior ubicado en Calceta. Unidad educativa que nace en el año 1999 como instituto y en el mes de abril del mismo año se convierte en universidad. La ESPAM oferta carreras de Agroindustria, Medio Ambiente, Agrícola y Pecuaria, para luego incorporar las carreras de Informática, Administración Pública, Administración de Empresas y Turismo. Ante lo cual, cuenta con 234 empleados y 18 departamentos, entre Consejo Politécnico, Rectorado, Vicerrectorados y Coordinaciones. (Escuela Superior Politécnica Agropecuaria de Manabí, s.f.).

\section{Metodología}


La investigación se realizó en el ESPAM MFL. La población objetivo está conformada por 234 empleados que de acuerdo al orgánico estructural pertenecen a las 25 diferentes Direcciones, Coordinaciones, Rectorado y Consejo Politécnico.

Para el levantamiento de información se aplicaron dos instrumentos diferentes: empleados por un lado y directores, jefes y coordinadores departamentales por otro.

El objetivo del primer instrumento es identificar los estilos de liderazgo predominantes en todos los directores, jefes y coordinadores departamentales del ESPAM MFL, mientras que el segundo instrumento permitirá conocer el nivel de satisfacción laboral de los empleados, respecto de sus directores, jefes y coordinadores.

Para realizar la evaluación a los directores, jefes y coordinadores departamentales se aplicó el cuestionario del Grid Gerencial, el cual permite identificar cinco estilos de liderazgo: gerencia empobrecida, autoridad y obediencia, gerencia club social, gerencia equilibrada o de medio camino y administración participativa o de equipo, siendo el estilo de Administración Participativa o de Equipo el más deseable, por ser el más eficaz (López J. A., 2015).

El cuestionario del Grid Gerencial está compuesto por 35 preguntas, donde las personas encuestadas seleccionan con una $X$, la respuesta que más se acerque a su forma de pensar y actuar ante dicha situación. Las preguntas exponen una situación y las cinco respuestas describen un intervalo de frecuencias (siempre, frecuentemente, ocasionalmente, raramente, nunca). Una vez que se obtienen las puntuaciones de las preguntas realizadas en el cuestionario se extraen dos dimensiones: la primera valora el estilo de liderazgo basado en la exigencia en las tareas y la segunda valora el estilo enfocado en las personas Finalmente ubicamos las puntuaciones de las dos dimensiones en el Grid Gerencial y obtenemos la orientación que tienen los directores, jefes y coordinadores departamentales en la ESPAM MFL. (Peñarreta, 2014).

Con el propósito de determinar el nivel de satisfacción de los empleados se aplicó un cuestionario con 20 preguntas realizado por Dunia Peñarreta (2014), el cual sigue los siguientes lineamientos o guías: Grid Gerencial, la encuesta de satisfacción laboral de Margarita Chiang y el cuestionario de satisfacción laboral de Warr, Cook y Wall (pp. 67-71)

Esa encuesta se aplicó de forma anónima a todos los empleados, donde las preguntas se orientaron a conocer la opinión y satisfacción de la relación laboral establecida con su director, jefe o coordinador.

Además, la encuesta realizada se ajustó a la escala Likert, donde "el encuestado tiene cinco opciones a elegir, de las cuales dos de ellas son extremas (una positiva y otra negativa), dos son medias (una positiva y una negativa) y otra es neutra. Es decir, que se establece tres niveles de satisfacción laboral: insatisfecho (I), medianamente Satisfecho (MS) y altamente satisfecho (AS). Cada afirmación del cuestionario tendrá un puntaje con valores que van de 1 a 5 puntos" (Peñarreta, 2014).

Las encuestas se aplicaron a lo largo de un mes, ya que se realizó en horas de la tarde, posteriores al almuerzo, con la debida de la institución, y dando a conocer al personal que son de 
estricto carácter confidencial, donde la opinión y veracidad de las mismas son de gran relevancia para el desarrollo de la investigación.

A continuación se presenta un resumen de los resultados obtenidos.

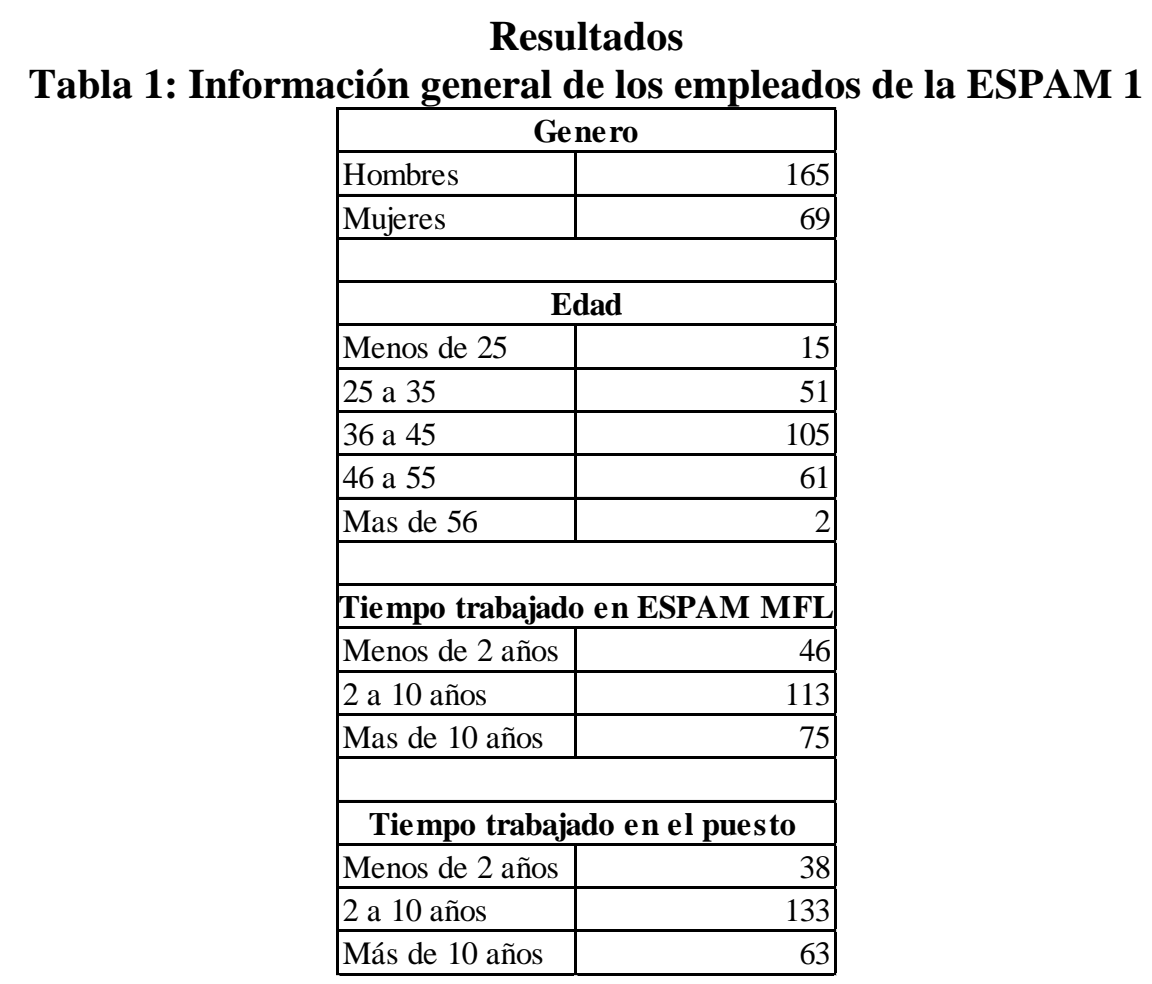

Nota: Tomado Escuela Superior Politécnica Agropecuaria de Manabí. (s.f.). espam.edu.ec. Obtenido de espam.edu.ec. Datos que comprenden la distribución del personal por género, edad, tiempo de relación laboral y tiempo por puesto.

De la información recogida, se puede ver que la mayor cantidad de empleados son hombres, y que predominan los empleados antiguos, con más de 2 años en la institución, siendo el grupo más importante el que tiene edades comprendidas entre los 36 a los 45 años.

Además se establece que los empleados según las carreras universitarias que oferta la institución son:

\section{Tabla 2:}




\begin{tabular}{|c|c|c|}
\hline \multirow{2}{*}{ CARRERAS } & \multicolumn{2}{|c|}{ PERSONAL } \\
\hline & FEMENINO & MASCULINO \\
\hline TTHH & 3 & 6 \\
\hline Empresas & 1 & 0 \\
\hline Pública & 1 & 0 \\
\hline Informática & 1 & 3 \\
\hline Agrícola & 4 & 22 \\
\hline Ambiental & 1 & 2 \\
\hline Veterinaria & 2 & 2 \\
\hline Turismo & 2 & 0 \\
\hline Idiomas & 2 & 0 \\
\hline Cood. Academica & 1 & 0 \\
\hline Evaluación & 1 & 0 \\
\hline Investigación & 1 & 2 \\
\hline Financiero & 1 & 14 \\
\hline Agroindustria & 1 & 12 \\
\hline Asesoría Juridica & 3 & 1 \\
\hline Planificación & 0 & 3 \\
\hline Postgrado & 3 & 6 \\
\hline Secretaria General & 6 & 6 \\
\hline Dir. Tecnologica & 1 & 4 \\
\hline Guardia & 1 & 13 \\
\hline Auxiliar Limpieza & 16 & 35 \\
\hline Mantenimiento & 1 & 12 \\
\hline Nivelación & 11 & 0 \\
\hline Unidad Transporte & 2 & 9 \\
\hline Vicerrectorado Extensión & 1 & 13 \\
\hline Vicerrectorado Académico & 3 & 4 \\
\hline Rectorado & 2 & 0 \\
\hline Unidad Software & 0 & 2 \\
\hline TOTAL & 69 & 165 \\
\hline
\end{tabular}

Nota: Tomado Escuela Superior Politécnica Agropecuaria de Manabí. (s.f.). espam.edu.ec. Obtenido de espam.edu.ec. Número de Empleados de la ESPAM perteneciente a cada Dirección divido por género.

\section{Satisfacción laboral}

Se aplicaron las encuestas de satisfacción laboral al universo y muestra de empleados de la ESPAM, esto es, 234 personas de los diferentes departamentos (ANEXO 2).

Los resultados fueron los siguientes:

\section{Tabla 3: Escala de satisfacción por número de empleados de la ESPAM}




\begin{tabular}{|c|c|c|}
\hline \multirow{4}{*}{} & $\begin{array}{c}\text { Num. De } \\
\text { Empleados }\end{array}$ & $\begin{array}{c}\text { Escala de } \\
\text { Satisfacción }\end{array}$ \\
\cline { 2 - 3 } & 14 & 1 \\
\cline { 2 - 3 } & 13 & 2 \\
\cline { 2 - 3 } & 29 & 3 \\
\cline { 2 - 3 } & 77 & 4 \\
\cline { 2 - 3 } & 101 & 5 \\
\hline Total & 234 & 6 \\
\hline
\end{tabular}

Nota: Tomado de Restrepo (2013) Referencia propia de Escala Utilizada para medición de satisfacción laboral en la ESPAM.

\section{Tabla 4: Frecuencia de Calificaciones}

\section{FRECUENCIA}
1 Nunca
2 Rara vez
3 Ocasionalmente
4 Frecuentemente
5 Siempre

Nota: Tomado de Restrepo (2013) Referencia propia de Escala Utilizada para medición de satisfacción laboral en la ESPAM.

En porcentajes los resultados obtenidos son:

$\checkmark$ Empleados insatisfechos: $12 \%$

$\checkmark$ Empleados medianamente satisfechos: $12 \%$

$\checkmark$ Empleados satisfechos: $76 \%$

Como se puede observar, los resultados recopilados demuestran que existe un buen índice de satisfacción laboral con un $76 \%$ que lideran los resultados, seguidos de un empate del $12 \%$, tanto de empleados insatisfechos y medianamente satisfechos.

\section{Encuesta de Liderazgo}

Esta encuesta (ANEXO 3) fue aplicada a los 18 directivos de la institución, quienes tienen a su cargo algún equipo de talento humano. En el cuestionario realizado, se buscó saber la orientación del liderazgo de la institución, incidido en las personas o a la producción de las mismas, así como el estilo de liderazgo, para lo cual se llevaron los resultados a la matriz Grid Gerencial.

Dichos resultados obtenidos en la encuesta, en cuanto a la orientación fueron los siguientes:

$\checkmark$ Orientación a las personas: 8

$\checkmark$ Orientación a la producción: 7

Dichos resultados se traducen en que la preocupación que el líder tiene hacia la tarea (o producción en el eje de las x) y el nivel de interés por el bienestar de las personas (eje de las y), es alta, ya que mientras más afuera y a la derecha se ubique en la matriz, se acerca al liderazgo ideal creador de equipos de trabajo. 
Por tanto, al llevar estos resultados al Grid Gerencial, el resultado obtenido se traduce en: Dirección en equipo, alto en la orientación a las tareas y alto en la orientación a las personas, tal como se muestra en el siguiente gráfico.

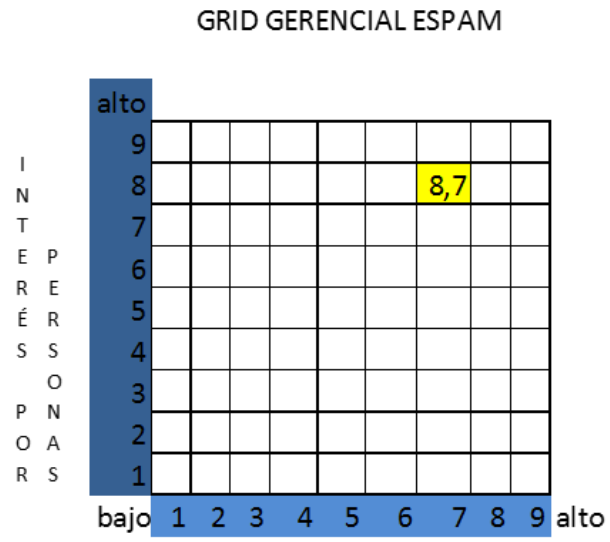

INTERES POR LAS TAREAS

Figura 1: Grid Gerencial de la ESPAM descripción grafica de los niveles de Dirección en Equipo los que se visualizan altos en nivel de tareas y orientación a las personas. Adaptado de Dumia Peñarreta (2014), Warr, Cook y Wall (pp.67-11)

Al tener un índice de satisfacción laboral superior al 70\%, se considera éste como bueno, existe un ambiente donde se fomenta el trabajo en equipo y la interdependencia de las expectativas tanto individuales como organizacionales

Para establecer el interés por las personas (liderazgo) y el nivel de satisfacción del personal, se establece la siguiente relación.

\section{Tabla 5: Nivel de relación de Liderazgo y Satisfacción Laboral INTERES POR LAS} PERSONAS

\begin{tabular}{ll} 
Liderazgo & Satisfacción \\
2 & $\mathbf{1}$ \\
4 & 2 \\
6 & $\mathbf{3}$ \\
8 & 4 \\
9 & 5 \\
\hline
\end{tabular}

Nota: Tomado del Estudio realizado referencia propia en el interés de los empleados para determinar la incidencia de la satisfacción laboral

Dónde:

\begin{tabular}{ll}
\multicolumn{2}{c}{ Tabla 6: Nivel de liderazgo } \\
\hline LIDERAZGO \\
\hline 2 & 0 \\
4 & MAYOR A 0 HASTA 3 \\
\hline
\end{tabular}




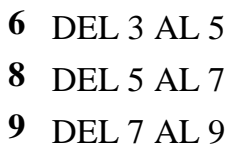

Nota: Referencia propia de Escala Utilizada para medición de satisfacción laboral en la ESPAM, datos obtenidos en encuesta elaborado y realizada a funcionarios

\section{Se obtiene la siguiente relación:}

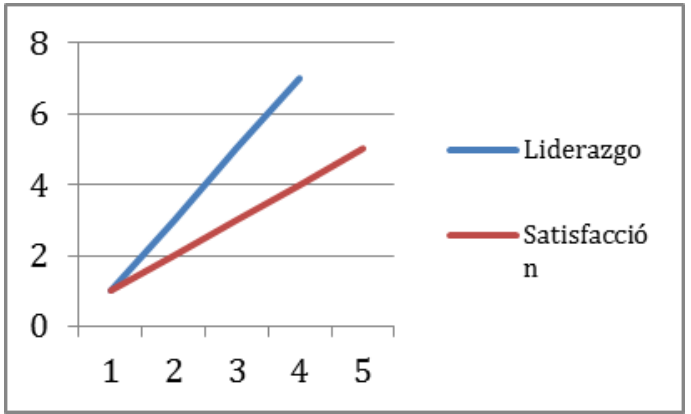

Figura 2: Representación Gráfica del nivel de liderazgo tomado de encuestas a personal de la ESPAM para la obtención de resultados en estudios de incidencia de satisfacción laboral. Adaptación y guía Dumia Peñarreta (2014), Warr, Cook y Wall (pp.67-11)

Respecto al liderazgo por la producción y la satisfacción laboral se establece la siguiente relación:

\section{Tabla 7: Niveles de interés por Producción INTERES POR LA PRODUCCIÓN}

\begin{tabular}{ll}
\hline Liderazgo & Satisfacción \\
1 & $\mathbf{1}$ \\
3 & 2 \\
5 & $\mathbf{3}$ \\
7 & 4 \\
& 5 \\
\hline
\end{tabular}

Nota: Tomado de Restrepo (2013) esto se usa como Referencia para la Escala Utilizada para medición de satisfacción laboral en la ESPAM mediante encuesta realizada.

Dónde:

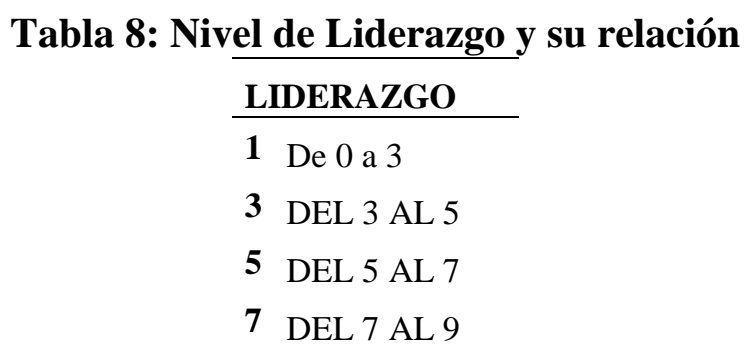

Nota: Tomado de los datos arrojados de relación del Liderazgo con la Satisfacción laboral para determinar la incidencia.

Se obtiene: 


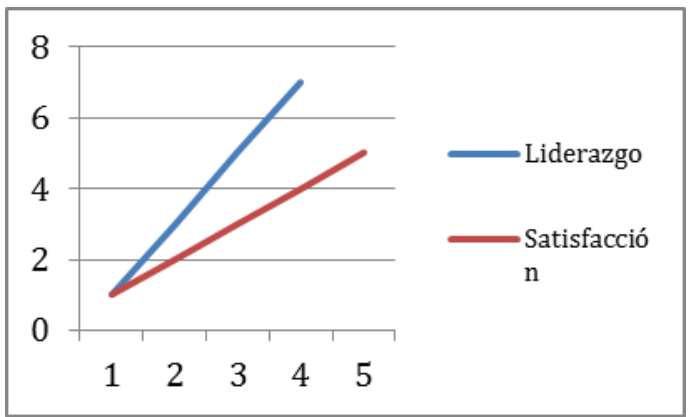

Figura 2: Representación Gráfica de los resultados obtenidos tomado de encuestas a personal de la ESPAM para la obtención en estudios de incidencia de satisfacción laboral. Referencia propia.

La atención que dan la más alta satisfacción del personal se da en las preguntas relacionadas a la buena relación laboral con el jefe, seguida por la satisfacción en cuanto a la comunicación existente y la libertad para usar el criterio propio a la hora de elegir el método de trabajo. Esto demuestra que hay un buen estilo de liderazgo, orientado a las personas. Lo que faltó sin embargo, para completar este estudio sería el análisis de los planes de trabajo y metas de la institución para poder conocer si realmente el liderazgo está funcionando para los fines de la ESPAM, aunque de lo que se pudo investigar en cuanto a dicha institución, ha tenido un avance notable en los últimos años, como se menciona en un apartado anterior de este estudio.

\section{Conclusiones}

Del estudio realizado se concluye que el estilo de liderazgo de la ESPAM, de manera general, es un liderazgo ideal, con un balance adecuado entre la orientación a los empleados y a los resultados. De acuerdo a los resultados obtenidos, en la ESPAM existe buen liderazgo de tipo Situacional, ya que se muestra una orientación al personal en el nivel 8/9, caracterizado por apoyo al equipo, actitud de guía y buen manejo de conflictos, así como buena relación líder subordinado.

En la investigación realizada a los líderes de la institución se encontró que todos los líderes demuestran un interés grande por la producción, pero permiten a sus subordinados realizar el trabajo de manera independiente, dando guía más que órdenes. Esto se explica al tener un equipo humano conformado por profesionales calificados y experimentados, que pueden realizar su trabajo con autonomía y no necesitan un excesivo control de sus jefes.

Por otra parte se encontró un 76\% de satisfacción de los empleados, que muestra su conformidad con el trato recibido por sus jefes y las condiciones de trabajo, así como el alto nivel de compromiso con la institución.

Los altos niveles de liderazgo y satisfacción hallados, permiten concluir que existe una clara relación entre estos dos factores, por lo cual la hipótesis de la presente investigación se cumple. Los resultados de la investigación señalan que existe un estilo de liderazgo situacional ideal, lo que se refleja en la satisfacción de los empleados. 
Las limitaciones de la investigación, fueron principalmente dos: 1) No se pudo analizar la satisfacción laboral por área de trabajo, sino de manera general. 2) No se permitió analizar el liderazgo individual, sino general. Esto fue por pedido expreso de la universidad de que las encuestas sean anónimas. Un estudio por área y por líder hubiera permitido realizar otro tipo de análisis más profundo.

\section{Recomendaciones}

Si bien es cierto que los resultados arrojados por el estudio avalan la hipótesis planteada, también existe el riesgo de que sea un resultado aislado, por lo cual este tipo de estudios se deben realizar de manera periódica. Se debe recordar que el índice de satisfacción de los empleados toma en cuenta el sentir de los mismos sobre lo vivido, mientras que los resultados del Grid Gerencial toman en cuenta la visión de los líderes sobre lo que desean que sea su gestión, por lo que se hace indispensable el seguimiento de estas variables.

Se recomienda a la ESPAM realizar un estudio del Grid Gerencial y satisfacción laboral por áreas, lo cual dará excelentes herramientas a la organización para identificar dónde mejorar o qué modelos replicar en las demás áreas. Una recomendación final sería realizar un estudio similar sumando una variable adicional que sería el plan estratégico de la institución con el fin de conocer el grado de interacción e incidencia del estilo de liderazgo frente a la satisfacción laboral y cumplimiento de los objetivos y metas.

\section{Bibliografía}

Arribas, J. I. (21 de Mayo de 2013). http://jma-asesores.com/. Recuperado el 27 de junio de 2016, de http://jma-asesores.com/12-preguntas-clave-para-la-medicion-del-clima-laboral/

Atalaya, M. (1999). Satisfacción Laboral y Productividad. Revista de Psicología, 46.

Bethere. (20 de 07 de 2012). http://webethere.com. Recuperado el 23 de 09 de 2016, de http://webethere.com/blog/2012/07/20/la-importancia-de-las-relaciones-laborales/

Blog de Directivos. (21 de 11 de 2014). Blogdedirectivos.es. Recuperado el 23 de 09 de 2016, de http://blogdedirectivos.es/liderazgo-empresarial/

Cevallos, V. (2013). Elempleo.com. Recuperado el 23 de 09 de 2016, de http://www.elempleo.com/colombia/consejos_profesionales/espacios-adecuados-favorecen-unmejor-desempeno-laboral--/12918924

(2000). En I. Chiavenato, Administración de Recursos Humanos (pág. 149). Santa Fé de Bogotá, Colombia: McGRAW-HILL.

Chiavenato, I. (2009). Administración de los Recursos Humanos. México: Mac Graw Hill.

Chiavenato, I. (2009). Administración de Recursos Humanos. Mexico: Mac Graw Hill.

Chruden, H. y. (1999). Administración de Personal. México: Compañía Editorial Continental. 
Clement, A. (2011). Comoserunbuenlíder.com. Recuperado el 23 de 09 de 2016, de http://comoserunbuenlider.com/blog/la-importancia-de-ser-un-buen-lider.html

Cuena, P. (2005). La dirección de comunicación en el ámbito universitario: Comunicaciòn interna y comunicación externa. Diálogo Iberoamericano. Granada.

Daft, R. (2007). La experiencia del liderazgo. En R. Daft, La experiencia del liderazgo (pág. 27). Madrid: Ediciones Paraninfo.

Elias, J., \& Mascaray, J. (2003). Más allá de la comunicación interna. La intracomunicación. Barcelona: Gestion 2000.

Escuela Superior Politécnica Agropecuaria de Manabí. (s.f.). espam.edu.ec. Obtenido de espam.edu.ec

Espinosa, C. (2011). Psicólogos en línea. Obtenido de https://psicologosenlinea.net/1785-liderazgosituacional-diferentes-conceptos-de-liderazgo-situacional-teoria-situacional-de-hersey-blanchardy-teoria-del-camino-meta.html\#ird2ddq2d

Fernandez, C. (2002). La comunicación en las organizaciones (Segunda ed.). Trillas.

Figueroa, D. (2009). Universidad de Concepción. Recuperado el 2016, de http://www.udec.cl/exalumnos/node/1550

Flores, C. (2012). www.prevenciónintegral.com. Recuperado el 23 de 09 de 2016, de http://www.prevencionintegral.com/canal-orp/papers/orp-2012/evaluacion-satisfaccion-laboraloverall-en-docentes-nivel-medio-superior

García, M. (Julio de 2013). Clima Organizacional y su diagnóstico. Una aproximación coinceptual. Redalyc(42), 43-61.

Gerencie.com. (10 de 09 de 2008). http://www.gerencie.com. Recuperado el 23 de 09 de 2016, de http://www.gerencie.com/el-recurso-humano-es-quizas-el-mejor-activo-de-la-empresa.html

Great Place to Work. (2016). Great Place to Work. Recuperado el 2016, de http://www.greatplacetowork.com.ec/acerca-de-nosotros/nuestra-historia

Great Place to Work Institute. (2016). http://www.greatplacetowork.com.ec. Obtenido de http://www.greatplacetowork.com.ec: http://www.greatplacetowork.com.ec/acerca-denosotros/nuestra-historia

Guerrero, B. (1 de diciembre de 2013). Players of Life Business and Lifestyle Magazine. Obtenido de Players of Life: http://www.playersoflife.com/articulo.php?id=4113

Hersey, \& Blanchard. (1969). Management of Organizational Behavior.

Kotter, J. (1996). Leading Change. Why transformation efforts fail. En J. Kotter, Leading Change. Why transformation efforts fail (pág. 127). Boston: Harvard Business Review.

Kotter, J. P. (1996). Leading Change. Harvard Business Review. 
López, H. F. (09 de 03 de 2011). Recuperado el 23 de 09 de 2016, de www.grandespymes.com.ar: http://www.grandespymes.com.ar/2011/03/09/de-que-depende-que-una-empresa-sea-exitosa/

Maxwell, J. (2005). Líder de 360 grados. Nashville: Líder Latino.

Metamanagers. (2016). Metamanagers. Recuperado el 2016, de http://www.metamanagers.com/documents/Liderazgo_Situacional.pdf

Muñiz, R. (1987). Marketing en el siglo XXI. En R. Muñiz, marketing en el siglo XXI.

Muñiz, R. (2012). Marketing-XXI.

Muñiz, R. (2016). Marketing21. Recuperado el 2016, de http://www.marketing-xxi.com/liderazgosituacional-modelo-kenneth-blanchard.html

Naranjo, M. (2016). La comunicación organizacional. Quito, Ecuador: El Conejo.

Peñarreta, D. (marzo de 2014). La influencia de los estilos de liderazgo en los niveles de satisfacción. Quito, Ecuador: Universidad Andina Simón Bolívar.

Peralta, R. (26 de junio de 2002). Gestiopolis.com. Recuperado el 28 de Junio de 2016, de http://www.gestiopolis.com/el-clima-organizacional/

Programa Misión COPEME. (2009). Medición del Clima Laboral para IMF’S. Lima: Copeme.

Quintana, D. A. (2013). Definiciones y Dimensiones del Clima Organizacional. Centro de Desarrollo Gerencial de Venezuela, 1.

Ramírez, R. (03 de 2008). Spentamexico.org. Recuperado el 23 de 09 de 2016, de http://www.spentamexico.org/v3-n1/3(1)\%20143-185.pdf

Restrepo, A. M. (04 de 12 de 2013). http://www.scielo.org.co/. Obtenido de http://www.scielo.org.co/pdf/adter/n24/n24a8.pdf

Revelo, B. (2016). Sociedad. En B. Revelo, Sociedad (págs. 20-24). Quito: Planeta.

Sánches, E., \& Rodríguez, A. (2010). 40 Años de la teoría del liderazgo situacional: una revisión. Redalyc, 42(1), 25-39.

Sánchez, M. (2005). Comunicación interna en la universiddad: El reto de conseguir la participacion de los universitarios. Madrid: Colección Comunicación 2000.

Sharingideas. (02 de 2014). http://sharingideas-josecavd.blogspot.com/. Obtenido de Sharingideas: http://sharingideas-josecavd.blogspot.com/2014/02/modelo-de-liderazgo-situacional-de.html

Varela, R. (18 de 06 de 2015). Joblers.net. Recuperado el 23 de 09 de 2016, de http://blog.joblers.net/indicadores-de-clima-organizacional.html

Villarreal, S. (03 de 02 de 2013). America Economía. Recuperado el 23 de 09 de 2016, de http://www.americaeconomia.com/analisis-opinion/el-sentido-de-pertenencia-un-activo-vecesolvidado-en-la-empresa 


\section{Anexos}

\section{Anexo 1}

\section{Organigrama Espam}

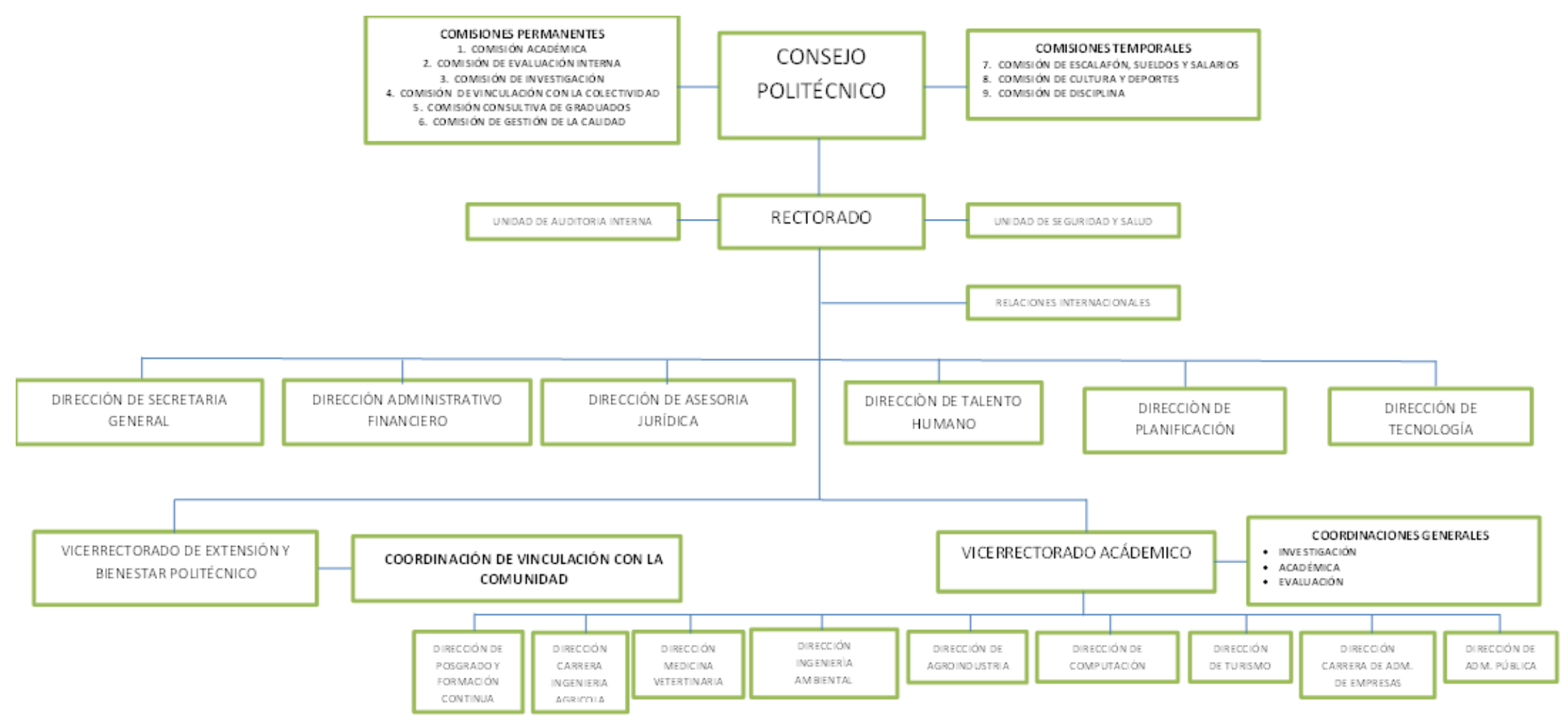




\title{
DIRECCIONES DE CARRERA
}

\author{
irección Carrera De Ingeniería Agrícola \\ irección De Medicina Veterinaria \\ irección De Ingeniería Ambiental \\ irección De Agroindustrias \\ irección De Computación \\ irección De Turismo \\ irección De Carrera De Administración De Empresas \\ irección De Administración Pública \\ irección De Secretaria General \\ irección Administrativo Financiero \\ irección De Asesoría Jurídica \\ irección De Talento Humano \\ irección De Planificación \\ irección De Posgrado Y Formación Continúa
}

DIRECCIONES DEPARTAMENTALES 


\section{Anexo 2}

\section{ENCUESTA GENERAL DE SATISFACCIÓN LABORAL}

La encuesta es anónima y los resultados servirán para fines estrictamente académicos. Los datos Ie se solicitan tienen como objetivo conocer su sentir respecto a distintos aspectos en el ámbito labo de ESPAM MFL. Se presentan varias opciones (de Muy Insatisfecho a Muy Satisfecho).

INDICACIONES: marque con un círculo alrededor del número de la alternativa que considere más cercana a su preferencia o que mejor represente su grado de satisfacción.

\begin{tabular}{|c|c|c|c|}
\hline GENERO & EDAD & $\begin{array}{c}\text { TIEMPO TRABAJADO EN } \\
\text { ESPAM MFL }\end{array}$ & $\begin{array}{c}\text { TIEMPO TRABAJADO } \\
\text { EN EL PUESTO }\end{array}$ \\
\hline \multirow[t]{2}{*}{ MASCULINO } & Menos de 25 & Menos de 2 anos & Menos de 2 anos \\
\hline & 25 a35 & & \\
\hline \multirow[t]{3}{*}{ FEMENINO } & 36 a 45 & 2 a 10 anos & 2 a 10 anos \\
\hline & 46 a 55 & & \\
\hline & Más de 56 & Más de 10 anos & Más de 10 anos \\
\hline
\end{tabular}

MUY

1. ¿Respecto a la toma de decisiones de mi jefe en mi área de trabajo, estoy?

2. ¿Respecto a la libertad que se me otorga para elegir mi propio método de trabajo, estoy?

3. ¿Respecto al trato igualitario que debe tener mi 1 jefe, con los miembros del grupo, estoy?

4. ¿Respecto a la atención que se me otorga a mis sugerencias, es toy?

5. ¿Respecto a la motivación que ejerce mi jefe, en incentivar la competitividad frente al resto de áreas, estoy?

6. ¿Respecto a la comunicación interna que existe dentro del área de trabajo, estoy?

7. ¿Respecto a la solución de conflictos por parte de mi jefe, es toy?

8. ¿Respecto al compromiso del jefe en la mejora de los procesos, estoy?

9. ¿Respecto a la supervisión del jefe, en mis funciones, estoy?

10. ¿Respecto a la comunicación de la toma de decisiones del jefe en mi área, estoy?
1
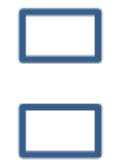

1

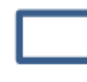

1

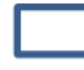

1

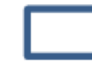

1

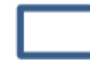

1

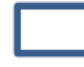

1
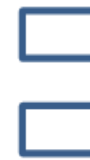

1
2

2

2

2

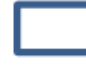

2

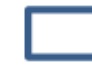

2

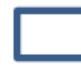

2
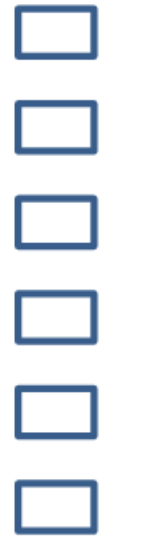

3

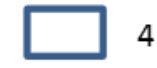

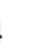

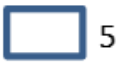

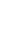
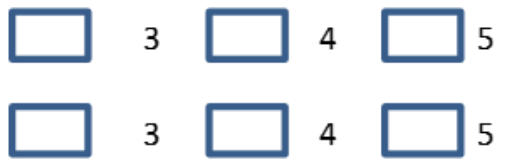

3
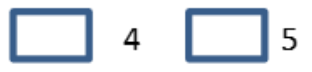

3
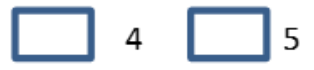

3

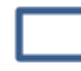

4

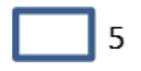

3
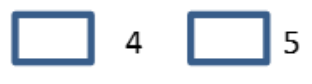

3
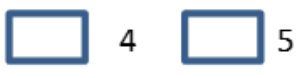

\section{2}

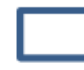

3
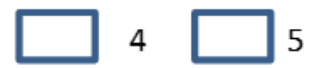

2

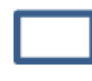

3
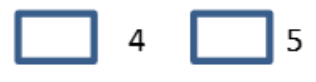

3
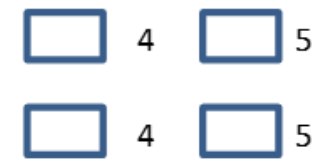

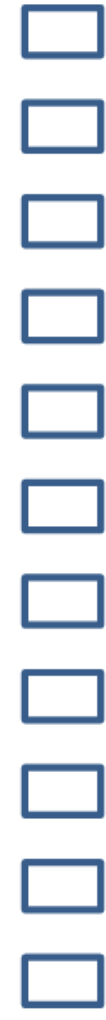




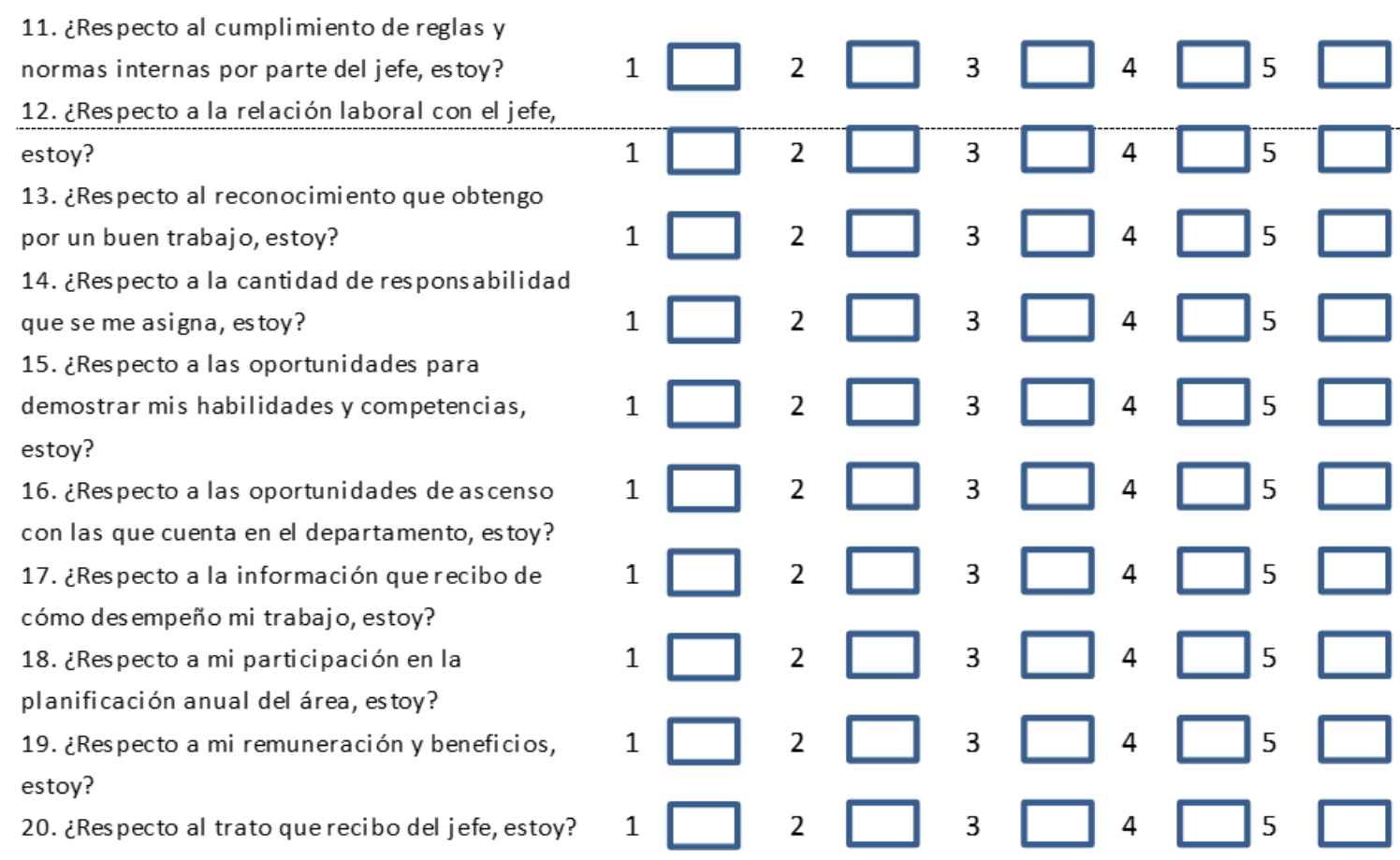

Muchas gracias por su colaboración!!

\section{Anexo 3}

TEST GRID GERENCIAL ESPAM

\section{DESCRIPCIÓN:}

A continuación se describen varios aspectos sobre el COMPORTAMIENTO de las personas en relación a al LIDERAZGO. Conteste a cada uno de ellos de acuerdo a la manera en que usted actuaría como dirige de su grupo u organización. Los fines de este documento son únicamente académicos.

\section{INSTRUCCIÓN:}

Ponga una $\mathrm{X}$ alrededor de la letra que describe la forma en que usted actuaría en cada una de las siguientes situaciones que indica.

EQUIVALENCIA: La equivalencia de las letras es la siguiente:
S: Siempre
F: Frecuentemente
O: Ocasionalmente
R: Raramente
$\mathrm{N}$ : Nunca 


\begin{tabular}{|c|c|c|c|c|c|}
\hline \multirow{2}{*}{$\frac{\text { CUESTIONARIO }}{\text { ¿Es muy probable que usted fuera el portavoz del grupo? }}$} & \multicolumn{5}{|c|}{ EQUIVALENCIA } \\
\hline & $\mathrm{S}$ & $\mathrm{F}$ & 0 & $\mathrm{R}$ & $\mathrm{N}$ \\
\hline 2 ¿Auspiciaría el que se trabaje en horas extras? & $\mathrm{S}$ & $\mathrm{F}$ & 0 & $\mathrm{R}$ & $\mathrm{N}$ \\
\hline 3 ¿Daría a los miembros total libertad en su trabajo? & 5 & $\mathrm{~F}$ & 0 & $\mathrm{R}$ & $\mathrm{N}$ \\
\hline 4 ¿Exigińa que todos sigan los mismos procedimientos? & $\mathrm{S}$ & $\mathrm{F}$ & 0 & $\mathrm{R}$ & $\mathrm{N}$ \\
\hline $\begin{array}{l}5 \text { ¿Permitiría que los miembros usen su propio criterio } \\
\text { para resolver problemas? }\end{array}$ & $\mathrm{s}$ & $\mathrm{F}$ & 0 & $\mathrm{R}$ & $\mathrm{N}$ \\
\hline \multirow{2}{*}{$\begin{array}{l}6 \text { ¿̇lnsistiría en que su grupo aventaje a los demás que } \\
\text { compiten con él? }\end{array}$} & $\mathrm{S}$ & $\mathrm{F}$ & 0 & $\mathrm{R}$ & $\mathrm{N}$ \\
\hline & & & & & \\
\hline 7 ¿Hablaría en representación del grupo? & $\mathrm{s}$ & $\mathrm{F}$ & 0 & $\mathrm{R}$ & $\mathrm{N}$ \\
\hline \multirow{2}{*}{$\begin{array}{l}8 \text { ¿Presiona a los miembros para lograr un trabajo } \\
\text { eficiente? }\end{array}$} & $\mathrm{s}$ & $\mathrm{F}$ & 0 & $\mathrm{R}$ & $\mathrm{N}$ \\
\hline & & & & & \\
\hline 9 ¿Pondría a prueba sus ideas en el grupo? & 5 & $\mathrm{~F}$ & 0 & $\mathrm{R}$ & $\mathrm{N}$ \\
\hline \multirow{2}{*}{$\begin{array}{l}10 \text { ¿Dejaría que los miembros hagan su trabajo de acuerdo } \\
\text { a lo que ellos creen que es la mejor manera? }\end{array}$} & 5 & $\mathrm{~F}$ & 0 & $\mathrm{R}$ & $\mathrm{N}$ \\
\hline & & & & & \\
\hline 11 ¿Trabajaría muy duro para conseguir un ascenso? & $\mathrm{s}$ & $\mathrm{F}$ & 0 & $\mathrm{R}$ & $\mathrm{N}$ \\
\hline 12 ¿Podría tolerar demora o indecisión? & $S$ & $\mathrm{~F}$ & 0 & $\mathrm{R}$ & $\mathrm{N}$ \\
\hline 13 ¿Hablaría por el grupo delante de visitas? & $\mathrm{s}$ & $\mathrm{F}$ & 0 & $\mathrm{R}$ & $\mathrm{N}$ \\
\hline 14 ¿Mantendría el trabajo a un ritmo acelerado? & $\mathrm{s}$ & $\mathrm{F}$ & 0 & $\mathrm{R}$ & $\mathrm{N}$ \\
\hline \multirow{2}{*}{$\begin{array}{l}15 \text { ¿Dejaría que los miembros (empleados) trabajen por su } \\
\text { cuenta? }\end{array}$} & $\mathrm{s}$ & $\mathrm{F}$ & 0 & $\mathrm{R}$ & $\mathrm{N}$ \\
\hline & & & & & \\
\hline \multirow{2}{*}{$\begin{array}{l}16 \text { ¿Arreglaría los conflictos que se produjeron en el } \\
\text { grupo? }\end{array}$} & 5 & $\mathrm{~F}$ & 0 & $\mathrm{R}$ & $\mathrm{N}$ \\
\hline & & & & & \\
\hline 17 ¿Le ahogarían los detalles? & $\mathrm{s}$ & $\mathrm{F}$ & 0 & $\mathrm{R}$ & $\mathrm{N}$ \\
\hline \multirow{2}{*}{$\begin{array}{l}18 \text { ¿Representaría al grupo en reuniones con personal de } \\
\text { fuera? }\end{array}$} & $\mathrm{s}$ & $\mathrm{F}$ & 0 & $\mathrm{R}$ & $\mathrm{N}$ \\
\hline & & & & & \\
\hline \multirow{2}{*}{$\begin{array}{l}19 \text { ¿Le desagradaría dejar que los miembros actúen } \\
\text { libremente? }\end{array}$} & 5 & $\mathrm{~F}$ & 0 & $\mathrm{R}$ & $\mathrm{N}$ \\
\hline & & & & & \\
\hline & 5 & $\mathrm{~F}$ & 0 & $\mathrm{R}$ & $\mathrm{N}$ \\
\hline debe hacer? & & & & & \\
\hline 21 ¿Urgiría una mayor producción? & 5 & $F$ & 0 & $\mathrm{R}$ & $\mathrm{N}$ \\
\hline 22 ¿Delegaría a algunos miembros la autoridad que usted & $\mathrm{s}$ & $\mathrm{F}$ & 0 & $\mathrm{R}$ & $\mathrm{N}$ \\
\hline debería mantener? & & & & & \\
\hline 23 ¿Saldrían las cosas generalmente tal como las & $\mathrm{s}$ & $\mathrm{F}$ & 0 & $\mathrm{R}$ & $\mathrm{N}$ \\
\hline esperaba? & & & & & \\
\hline 24 ¿Permitiría un al to grado de iniciativa al grupo? & $\mathrm{s}$ & $\mathrm{F}$ & 0 & $\mathrm{R}$ & $\mathrm{N}$ \\
\hline 25 ¿Designaría a los miembros del grupo para tareas & 5 & $\mathrm{~F}$ & 0 & $\mathrm{R}$ & $\mathrm{N}$ \\
\hline especificas? & & & & & \\
\hline 26 ¿Estaría dispuesto a hacer cambios? & $\mathrm{s}$ & $\mathrm{F}$ & 0 & $\mathrm{R}$ & $\mathrm{N}$ \\
\hline 27 ¿Pediría que los miembros del grupo trabajen más & $\mathrm{s}$ & $\mathrm{F}$ & 0 & $\mathrm{R}$ & $\mathrm{N}$ \\
\hline intensamente? & & & & & \\
\hline 28 ¿Confiaría en que los miembros del grupo usen buen & $\mathrm{s}$ & $\mathrm{F}$ & 0 & $\mathrm{R}$ & $\mathrm{N}$ \\
\hline criterio? & & & & & \\
\hline 29 ¿Programaría el trabajo que debe hacerse? & 5 & $\mathrm{~F}$ & 0 & $\mathrm{R}$ & $\mathrm{N}$ \\
\hline 30 ¿Se negaría a explicar sus actuaciones? & $\mathrm{s}$ & $\mathrm{F}$ & 0 & $\mathrm{R}$ & $\mathrm{N}$ \\
\hline 31 ¿Trataría de convencer a los miembros del grupo que & $\mathrm{s}$ & $\mathrm{F}$ & 0 & $\mathrm{R}$ & $\mathrm{N}$ \\
\hline sus ideas son ventajosas para ellos? & & & & & \\
\hline 32 ¿Permitiría que el grupo trabaje a su propio ritmo? & $\mathrm{s}$ & $\mathrm{F}$ & 0 & $\mathrm{R}$ & $\mathrm{N}$ \\
\hline 33 ¿Urgiría para que el grupo supere su "récord" anterior? & $\mathrm{s}$ & $\mathrm{F}$ & 0 & $\mathrm{R}$ & $\mathrm{N}$ \\
\hline 34 ¿Actuaría sin consultar al grupo? & $\mathrm{s}$ & $\mathrm{F}$ & 0 & $\mathrm{R}$ & $\mathrm{N}$ \\
\hline 35 ¿Pediría que los miembros del grupo sigan las reglas y & $\mathrm{s}$ & $\mathrm{F}$ & 0 & $\mathrm{R}$ & $\mathrm{N}$ \\
\hline
\end{tabular}




\section{Anexo 4}

Calceta 02 de mays de 2016

Dra. C. Miryam Félix López

RECTORA DE LA ESPAM MFL

De mis consideraciones:

Estimada Rectora, por mecio del presente tengo a bien solicitar a usted, por motivo de encontrarme cursando mis ostudios de cuarto nivel para la obtención del titulo Magister en Dirección del Talento Humano, solicitarle la correspond ente autonzación para realizar en esta Instlución mi trajajo de Investgación, previo a la obtención del titulo de Magister en Direcc ón del Talerto Humano.

Esperando una respuesta favorable me suscr bo

Atentamente.

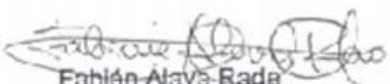

\section{Anexo 5}

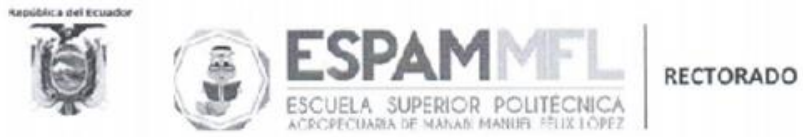

Calceta, 02 de mayo de 2016

Ingeniero

Fabián Eduardo Álava Rade

Ciudad.-

De mis ccns deraciones.

En atención a su oficio SN de fecha 02 de mayo de 2016. mediante el cual solicita autorización para realizar su trabajo de investigación en la Escuela Superor Politécnica Agropecuaria de Manabi Manuel Félix López, prevo a la obtención dol título do Magister on Dirección del Talento Humano, tengo a b en infomar que se concede la respectiva autorización.

Con la expresion de mi especial aprecio me remito cordialmente

Atentamente,

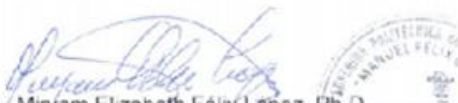

